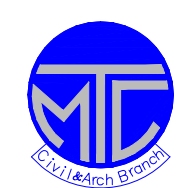

ICCAE

Military Technical College

Kobry Elkobbah,

Cairo, Egypt 7th International Conference

On Civil \& Architecture

Engineering

\title{
THE FORMATION OF SHEAR BAND AND THE BEHAVIOR OF REINFORCED SOIL SLOPES
}

\author{
Tarek N. Salem ${ }^{1}$, Khaled Hassan ${ }^{2}$, Mohsen Mashhour ${ }^{3}$, Ahmed AbuElella ${ }^{4}$
}

\begin{abstract}
The failure mechanism in slopes usually start with the formation of a shear band or in other words, the formation of a failure zone with higher shear stresses that eventually leads to the formation of a failure surface. The shear band shape is dependent upon the soil type or specifically the shear strength parameters, and it is not necessarily circular as most analysis tools assume. To prevent slope failures and allow for steeper and higher slopes of compacted soils, layers of reinforcements are arranged in soil slopes for stabilization to control the shear band and consequently shear failure. The special purpose geotechnical software Plaxis is used in the numerical analysis of slopes to identify the shear band for different soil types and to study the behavior of reinforced soil slopes. The studied parameters included, number of soil reinforcement layers, layer position, geogrid length, and slope angle are all presented in an optimized form. Results showed that for cohesive soils, the shear band is deep and can be clearly identified. On the other hand, for cohesionless soils, the shear band is shallow and took a block-like failure shape. Results also showed that the location of the reinforcement layers is more effective than the number of layers. Lower layers are subjected to higher tension forces and upper layers resist lower loads.
\end{abstract}

\section{KEY WORDS}

\footnotetext{
${ }^{1,2}$ Assoc. Prof., Dept. of Structural Eng., Faculty of Eng., Zagazig University, Zagazig, Egypt.

${ }^{3}$ Prof. Dept. of Structural Eng., Faculty of Eng., Zagazig University, Zagazig, Egypt.

${ }^{4}$ Assistant Lecturer, Dept. of Structural Eng., Faculty of Eng., Zagazig University, Zagazig, Egypt.
} 
Slope Stability; Numerical Analysis; Shear Band; Soil Reinforcement.

\section{INTRODUCTION}

Evaluating the stability of slopes in soil is an important, interesting, and challenging aspect of civil engineering. Concerns with slope stability have driven some of the most important advances in our understanding of the complex behavior of soils. Extensive engineering and research studies performed over the past 70 years provide a sound set of soil mechanics principles with which to attack practical problems of slope stability, Duncan and Wright [1].

Three types of slope failures are possible; base failure, toe failure, and face failure. In the case of the base failure, the surface of the sliding passes at some distance below the toe of the slope. Base failure generally develops in soft clays and soils with numerous soft seams. The top of the slope drops, leaving a vertical scarp, while the level ground beyond the toe of the slope bulges upward. Toe failures occur in steeper slopes. The top of the slope drops, while the soil near the bottom of the slope bulges outward. Face failures occur when a hard stratum limits the extent of the failure surface. The type of slope failure engineers most frequently encounter is the toe failure, Chen [2].

\section{SHEAR BAND FORMATION}

The shear band refers to the zone of maximum shear stress and strains, in which the failure surface can be identified inside this zone. In addition to gravity loads, when external forces are applied, both normal and tangential forces develop at particle contacts. All particles do not share the forces or stresses applied at the boundaries in equal manner. Each particle has different skeletal forces depending on the position relative to the neighboring particles in contact. Strong particle force chains form in the direction of major principal stress. The evolution and distribution of inter-particle skeletal forces in soils govern the macroscopic stress-strain behavior, volume change, and strength. As the soil approaches failure, buckling of particle force chains occurs and shear bands develop due to localization of deformation. However, significant softening can be caused by strain localization and development of shear bands, especially for dense soils under low confinement, Mitchell and Soga [3].

The rotating group of interlocked particles, which can be considered as a weak cluster, becomes more apparent as applied strains increase toward failure. The bands of large residual deformation, termed micro-bands by Kuhn [4], are where particle translations and rotations are intense as part of the strong force network. 
Kuhn [4] reports that their thicknesses are $1.5 D_{50}$ to $2.5 D_{50}$ in the early stages of shearing and increase to between $1.5 D_{50}$ and $4 D_{50}$ as deformation proceeds, in which $D_{50}$ is the sieve opening that passes $50 \%$ of the soil specimen in a sieve analysis test. This micro-band slip zone may eventually become a localized shear band.

Alshibli and Sture [5] observed the shear band formation in a direction diagonal to the principal stress directions in the laboratory by photo-elasticity testing technique. The deformation is localized, and the two soil bodies on opposite sides of the shear band act as rigid bodies. Strain localization tends to occur in soils that exhibit strainsoftening behavior, such as over-consolidated clay and dense sand under low confining pressure. This observation illustrates the difficulty in obtaining the material behavior from experimental measurements at the specimen boundaries, as these strains are different from the strains in the shear band where the actual shearing is occurring. The peak strength and the associated strain are specimen size dependent because of the progressive nature of shear band development.

X-ray computed tomography (CT) allows construction of a three-dimensional density profile inside a material by assembling X-ray radiographic two-dimensional images taken at different angles. The resolution of a CT scanner is determined by the dimensions of a source and a detector as well as their positions in relation to the test specimen. The technique has been used to examine the locations of shear zones within a specimen as local dilation inside the shear band gives low electron density (Desrues et al. [6]; Otani et al. [7]; Alshibi et al. [8]; Otani and Obara, [9]).

The thickness of the shear band depends on particle size as shown in Fig. 1, [10]. It increases with increasing displacement, but then reaches a constant value between 7 to 10 particle diameters when the displacement is more than 20 particle diameters (Scarpelli and Wood, [11]; Oda and Kazama, [12]). However, this does not mean that more particles are involved in the shear band. It is more likely that the local void ratio in the shear band is growing. The formation shear band in loose sands is discussed in Finno et al. [13]. Lesniewska and Morz [14], and Saada et al. [15] analyzed the evolution and propagation of shear bands using limit equilibrium approach and bifurcation analysis.

\section{REINFORCED SLOPES}

A solution is needed when a proposed slope is unsafe due to the increased disturbing force, or increased slope height, or slope angle, and/or reduction in the soil shear strength $(c, \phi)$ parameters, for a long-term analysis. The solution for such situation may be using soil reinforcements to increase the stabilizing force and increase the safety factor of that slope.

Reinforcement can be used to improve the stability of slopes and embankments, making it possible to construct slopes and embankments steeper and higher than would otherwise be possible. Reinforcement has been used in four distinct types of applications, Duncan and Wright [1]: 
1. Reinforced slopes, in which multiple layers of reinforcement at various elevations within fill slopes have been used to increase the factor of safety for slip surfaces that cut through the reinforcement, making it possible to construct slopes steeper than would be possible without reinforcement.

2. Reinforced embankments on weak foundations in which reinforcement at the bottom of an embankment on a weak foundation can increase the factor of safety for slip surfaces passing through the embankment, making it possible to construct the embankment higher than would be possible without reinforcement.

3. Reinforced soil walls or mechanically stabilized earth walls, in which several different proprietary systems have been developed for reinforced soil walls, which are used as alternatives to conventional retaining walls.

\section{ANALYSIS METHODOLOGY}

The special purpose finite element code Plaxis [16] is used in analyzing the slopes, in tracking the formation and evolution of shear bands, expecting the failure shape, and analyzing reinforced slope. The software has strong modeling capabilities allowing for modeling soil nonlinearity, creep, short and long term behavior, different soil models, etc. For the analysis of slopes, the software is able to represent stresses inside the soil slope in the form of shading in which higher stresses could be clearly identified with specific colors. In addition to shading, more pronounced displacement vectors, with higher displacements represented by longer vectors and vise verse, could also be drawn. The software has also the capability of analyzing reinforced slopes accounting for the tension stresses generated in each reinforcement layer. In the analysis, soil reinforcement layers could be arranged at different heights, with different lengths, and different spacing to achieve the highest possible factor of safety with the lowest possible reinforcement quantity. The most effective reinforcement layer position is chosen at the highest stress concentration zone.

\section{RESULTS ANALYSIS AND DISCUSSION}

Homogeneous soil slopes are analyzed with different soil types, slope configurations to track the formation of shear band and failure surface inside the studied slope. Of interest in this analysis are the failure type, starting point, and shear failure surface shape. Regarding the reinforced soil slopes, the analysis is mainly concerned with studying the reinforcement layers position, numbers, and lengths to maximize the safety factors of reinforced soil slopes, AbuElella [17].

\subsection{Results of Shear Band Formation}

The forthcoming parts will present the type, shape, and formation of shear bands for different soil types and slope configurations. The results are mainly presented in two forms, shear stress shading and displacement vectors. Fig. (2a and b) shows the effect of decreasing the friction angle $(\phi)$ from $40^{\circ}$ to $20^{\circ}$ on the location of the failure surface and shear band zone. Fig. 2a illustrates that the failure surface will be a face failure, in which the failure will occur in the slope face itself. Fig. $2 b$ shows that by decreasing the angle of internal friction $(\phi)$ from $40^{\circ}$ to $20^{\circ}$ the failure surface will be a toe failure and deeper than the first case. In addition, higher displacement vectors 
are also noticed as a result of reducing the friction angle. It is interesting to note that in many failures the toe point is a stress concentration point then the toe point has a higher possibility to be a point on the failure surface.

Fig. 3 shows the effect of soil angle of internal friction $(\phi)$ on the failure surface for lower values of soil cohesion, $\left(c=5 \mathrm{kN} / \mathrm{m}^{2}\right)$. The shear band is located within the top of slope and the failure surface will be a face failure. However, when no soil cohesion exists and pure friction soil is analyzed, the shear band could not be clearly identified and the failure surface will still be a face failure.

Fig. $4 a$ and $b$ shows the effect of soil cohesion on the shape of the shear band and the failure surface. The figures illustrate that when $c=20 \mathrm{kN} / \mathrm{m}^{2}$ and $(\phi)$ equals $20^{\circ}$, the failure surface will be somewhat shallow, and when the soil cohesion increased to $35 \mathrm{kN} / \mathrm{m}^{2}$ the failure surface will be deeper and the width of the shear band will be larger than the case of $c=20 \mathrm{kN} / \mathrm{m}^{2}$. The same Fig. illustrates the displacement vectors, which reflects the direction of the slope translation.

For the cases of smaller friction angle $(\phi)$ and higher cohesion (c) as in short term analysis, Fig. 5a shows the effect of soil cohesion on the failure surface shape. For $\phi$ $=5^{\circ}$ and soil cohesion is $100 \mathrm{kN} / \mathrm{m}^{2}$, the failure surface is more like a base failure, the shear band width will be large, and the displacement vectors also refer to the soil wedge which will be horizontally translated. Therefore, in cohesive soils the failure shape tends to be deep seated failure.

Fig. 5b shows the results for the same friction angle but with soil cohesion equals 50 $\mathrm{kN} / \mathrm{m}^{2}$. It is noticed that the failure surface is also a base failure, but the failure wedge is smaller and shallower than the case of $c=100 \mathrm{kN} / \mathrm{m}^{2}$, but the shear band can be easily distinguished in this case.

Fig. 6 illustrates the effect of load on the shear band formation. Fig. 6a shows the shear band for the unloaded case, and Fig. 6b shows the loaded case with somewhat large surface load of $50 \mathrm{kN} / \mathrm{m}^{2}$, in a gentle slope $3: 1$. It is clear that the displacement under the loading zone is large and the failure surface is forced to start at the end of the loaded length as a result of the presence of load. The greater the value of surface loads, the further tendency for the slope to fail. This failure trend is of great concern when calculating the bearing capacity of the embankment soil.

In conclusion, the shear band is found to be deep in cohesive soils, which refers to base failure that a higher cohesion results in a deeper shear band. When the soil cohesion increased, the width of the shear band increased and the area of the failure wedge is also increased. This may be attributed to the larger disturbing force needed to cause failure in a larger failure surface, or in other words, a larger failure surface is usually associated with larger resisting force. It is worth mentioning that the toe point, as a point of stress concentration, can be considered as a point of the initiation of the failure surface for most (c- $\phi)$ and $(\phi)$ slopes. However, for (c) slopes base failure usually dominates and the failure surface, and initiates under the toe point.

When the soil angle of internal friction increased, the shear band width is decreased especially in (c- $\phi$ ) slope. On the other hand, in $(\phi)$ slope, the shear band could not be 
clearly identified, but rather a failure wedge would be encountered. The reason for this observation may be attributed to the translation from base failure to toe failure then face failure, as a result of increasing $(\phi)$ value and decreasing (c). Therefore, the failure surface can be easily determined within the zone of shear band, and its shape is almost log spiral not circular for most soil types and slope characteristics.

\subsection{Analysis of Reinforced Slopes}

Layers of reinforcement are arranged all over the slope height for the purpose of increasing its stability, allowing higher surface loads, more heights, and steeper slope angles. The specific slope characteristics are; slope height of 20 meters, slope angle of about $63^{\circ}$ or $2 \mathrm{~V}: 1 \mathrm{H}$, and the soil shear strength parameters are $\mathrm{c}=20 \mathrm{kN} / \mathrm{m}^{2}, \phi=$ $20^{\circ}$, representing a homogeneous slope for long term analysis. The slope is reinforced with geogrid layers at a vertical spacing of $1.0 \mathrm{~m}$, and with strength parameter $\left(E A=1000 \mathrm{kN} / \mathrm{m}^{\prime}\right)$, covering the whole embankment breadth. A slope of such configuration will fail if unreinforced. For the unreinforced case, the factor of safety is less than 1, but after using the reinforcements the factor of safety reached 1.654. Fig. 7 shows the relation between forces in the geogrid reinforcements with depth of $(c-\phi)$ slope. The figure reflects that the maximum force is encountered at the middle third of the slope. Therefore, to enhance the safety factor one can strengthen the middle third of the slope only by adding a layer of soil reinforcements at that specific height.

Fig. 8 illustrates distribution of the forces in the geogrid when the reinforcements are placed in the lower half of the slope height. It is also noted that the reinforcement forces increased gradually and at the lower part, the forces jump from 6 to $48 \mathrm{kN} / \mathrm{m}^{\prime}$ in the first four meters, then gradually increase to reach $54 \mathrm{kN} / \mathrm{m}$ ' in the next four meters. The forces in the lower geogrid layers at toe are so small that it can be neglected.

Fig. 9 shows the same relation but for reinforcements arranged in the middle third of the slope height only. In this case, dense reinforcement layers resulted in an increase in the safety factor, and give more even distribution of the forces in the geogrid, keeping in mind that the maximum force in the geogrid must be less than the allowable values.

Fig. 10 shows the relation between the tension forces in the geogrid with depth for a granular slope with $(\phi)$ equals 40 degrees. The distribution of the forces in the geogrid for a $(\phi)$ slope differs from that of a $(c-\phi)$ slope. The maximum force in the geogrid is located at the lower part of the slope. It may be concluded, in this case, that reinforcements are only needed at the lower zone of a granular slope.

A slope height of 10 meters and soil shear strength parameters $c=15 \mathrm{kN} / \mathrm{m}^{2}$ and $\phi=$ $15^{\circ}$ is analyzed in the presence of soil reinforcements. For a geogrid with strength parameter $\left(E A=1000 \mathrm{kN} / \mathrm{m}^{\prime}\right)$, Fig. $11 \mathrm{a}$ and $11 \mathrm{~b}$ shows the distribution of the 
reinforcement tension forces with depth for two slopes of $(3 \mathrm{H}: 1 \mathrm{~V})$ and $(2 \mathrm{H}: 1 \mathrm{~V})$ respectively. It is clear that for a gentle, the position of maximum force in the geogrids move towards the slope crest, while for the steeper slope, the maximum force tends to be located towards the slope base (toe). The position of maximum force is very important in determining the zone that has to be reinforced.

Fig. 12 shows the relation between the induced geogrid forces for different slope angles with geogrid axial strength parameter $\mathrm{EA}=1200 \mathrm{kN} / \mathrm{m}$ '. When the slope angle is larger than $\left(65^{\circ}\right)$, the reinforcement layers should be arranged in the lower third of the slope. It is noticed that the forces in the geogrids increased with increasing the disturbing force due to the high slope angle $(\beta)$. Moreover, the factor of safety increased with increasing the allowable force in the geogrids. Gentle slopes gave even distribution of the reinforcement forces, and steeper slopes gave large differences between surch forces. If the slope angle is smaller than $\left(65^{\circ}\right)$, the reinforcement layers should be arranged in the middle half of the slope height. The middle half, in this case, is that starts above the lower quarter and extends up to the lower edge of the upper quarter; this is from the economic point of view. The increase in the factor of safety (F.S) gained from reinforcing the whole slope height is relatively small, and excluded for economical reasons.

Fig. 13 shows the relation between forces in the geogrids and depth for a vertical cut. It is clear that the maximum force is found at the bottom of the slope and its value is very large, which dictates the use high strength geogrids. In addition, reinforcement layers should be arranged closer to each other in the lowest part of the vertical cut.

The vertical distance between the reinforcement layers (Geogrids) has a great effect on the factor of safety. Smaller distances between the reinforcement layers resulted in higher safety factors and vice verse. Fig. 14 shows the relation between the vertical distance between geogrids and the safety factor (F.S).

\section{CONCLUSIONS}

1- The shear band zone is strongly affected by the soil cohesion (c), the higher the soil cohesion is the clearer, deeper, and wider the shear band is.

2- Keeping the soil angle of internal friction $(\phi)$ constant, while increasing the soil cohesion resulted in switching the failure surface from face failure to toe failure, then base failure.

3- In slopes characterized by the soil angle of internal friction only, $(\phi)$ slopes, the shear band is not clearly defined and only a failure wedge could be accurately observed.

4- For most ( $c$ and $c-\phi$ ) slopes, arranging the reinforcement in the middle third of the embankment has a great influence in increasing the safety factor. However, for $(\phi)$ slopes, the reinforcement layers and geogrids should be condensed at the lower third. Generally, if the slope angle is smaller than $\left(65^{\circ}\right)$, the reinforcement layers should be arranged and condensed in the middle half of the slope height. For slope angles larger than $\left(65^{\circ}\right)$, the reinforcement layers should be condensed in the lower third of the slope. 
5- The safety factor is inversely proportional with the vertical distance between the reinforcement layers, regardless of the slope soil type.

\section{REFERENCES}

[1] Duncan, J.M., and Wright, S.G., "Soil Strength and Slope Stability", John Wiley \& Sons, Inc., New York, (2005).

[2] Chen, F.H., "Soil engineering: Testing, Design, and Remediation", Edited by M.D. Morris, CRC Press, London, (2000).

[3] Mitchell, J.K., and Soga, K., "Fundamentals of Soil Behavior", $3^{\text {rd }}$ Edition, John Wiley \& Sons, Inc., New York, (2005).

[4] Kuhn, M.R., "Structured Deformation in Granular Materials", Mechanics of Materials, Vol. 31, pp. 407-429, (1999).

[5] Alshibli, K.A., and Sture, S., "Shear Band Formation in Plane Strain Experiments of Sand", ASCE, J. of Geotechnical and Geoenvironmental Eng., Vol. 126, No. 6, pp. 495-503, (2000).

[6] Desrues, J., Chambon, R., Mokni, M., and Mazerolle, F., "Void Ratio Evolution inside Shear Bands in Triaxial Sand Specimens Studied by Computed Tomography", Geotechnique, Vol. 46, No. 3, pp. 529-546, (1996).

[7] Otani, J., Mukunoki, T, and Obara, Y., "Application of X-Ray CT Method for Characterization of Failure in Soils", Soils and Foundations, Vol. 40, No. 2, pp. 113-120, (2000).

[8] Alshibli, K.A., Batiste, S.N., and Sture, S., "Strain Localization in Sand: Plane Strain versus Triaxial Compression", ASCE, J. of Geotechnical and Geoenvironmental Eng., Vol. 129, No. 6, pp. 483-494, (2003).

[9] Otani, J., and Obara, Y., "X-ray CT for Geomaterials: Soils, Concrete, Rocks, Balkema, Rotterdam, (2004).

[10] Oda, M., and Iwashita, K., (1999), "Mechanics of Granular Materials: An Introduction", Balkema, Rotterdam, (1999).

[11] Scarpelli, G., and Wood, D.M., "Experimental Observations of Shear Band Patterns in Direct Shear Tests", In: P.A. Vermeer and H.J.L. Luger (Eds.), Proceedings of the IUTAM Conference on Deformation and Failure of Granular Materials, Balkema, Rotterdam, pp. 473-484, (1982).

[12] Oda, M., and Kazama, H., "Microstructure of Shear Bands and Its Relation to the Mechanisms of Dilatancy and Failure of Dense Granular Soils", Geotechnique, Vol. 48, No. 4, pp. 465-581, (1998).

[13] Finno, R.J., Harris, W.W., Mooney, M.A., and Viggiani, G., "Shear Bands in Plane Strain Compression of Loose Sand", Geotechnique, Vol. 47, No. 1, pp. 149-165, (1997).

[14] Lesniewska, D., and Mroz, Z., "Limit Equilibrium Approach to Study the Evolution of Shear Band Systems in Soils", Geotechnique, Vol. 50, No. 5, pp. 521536, (2000).

[15] Saada, A.S., Liang, L., Figueroa, J.L., and Cope, C.T., "Bifurcation and Shear Band Propagation in Sands", Geotechnique, Vol. 49, No. 3, pp. 367-385, (1999).

[16] PLAXIS, "Finite Element Code for Soil and Rock Analysis", Ver. 7.20, Plaxis B.V., (2001). 
[17] AbuElella, A.A., "Numerical Assessment of Loaded and Reinforced Earth Slopes", M.Sc. Thesis, Faculty of Engineering, Zagazig University, Zagazig, Egypt, (2006)

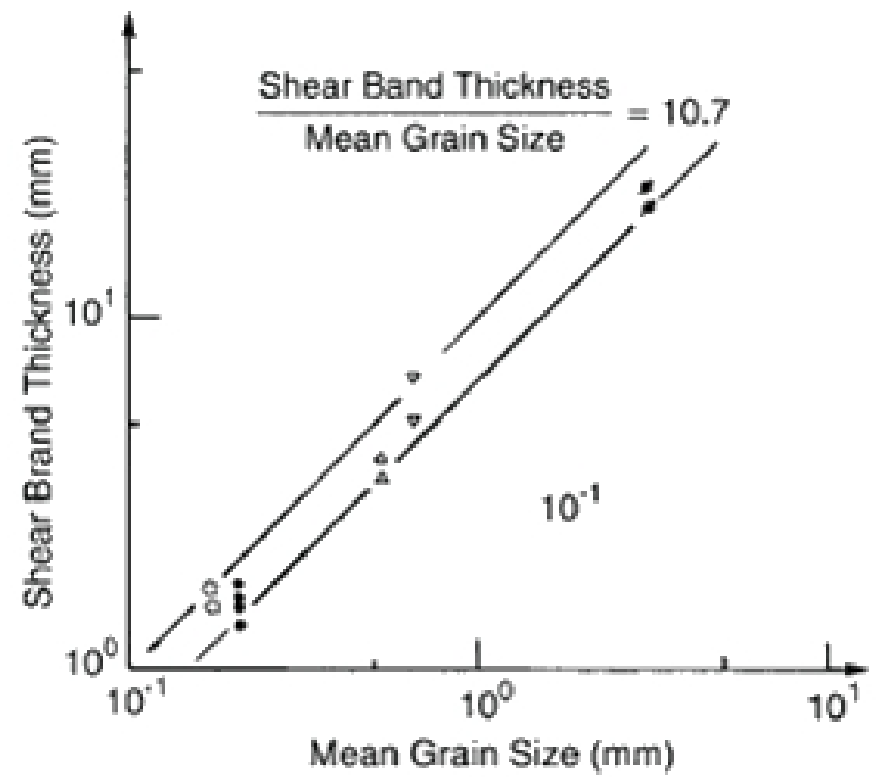

Fig. 1: Thickness of Shear Band as a Function of Particle Size, after Oda and Iwashita, [10].
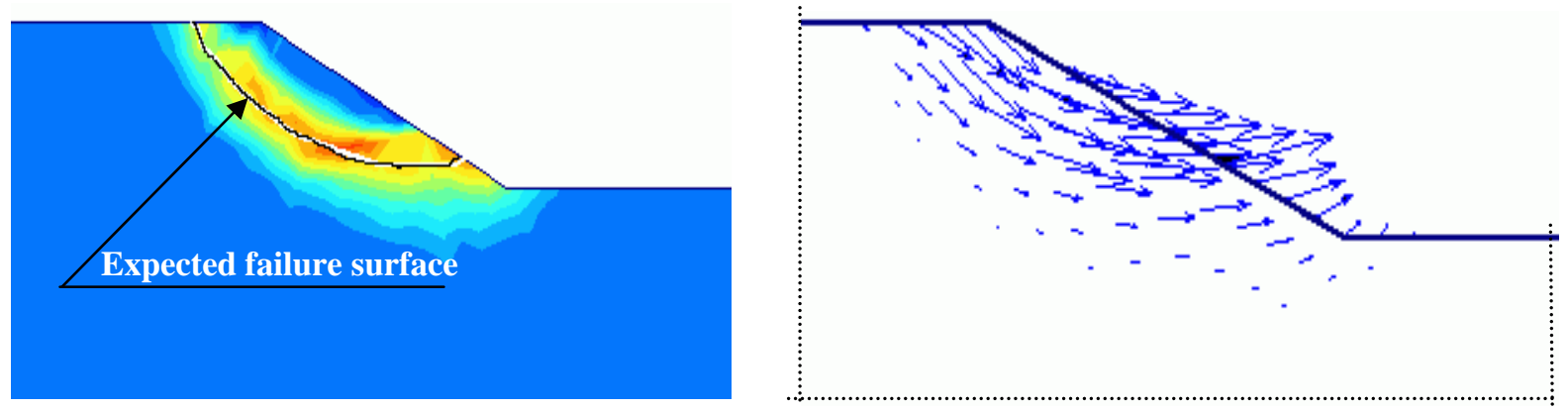

Fig. 2a: Shear Stress Shading (Shear Band) and Displacement Vectors for Slope with $\mathrm{c}=15 \mathrm{kN} / \mathrm{m}^{2}, \phi=40^{\circ}$, Slope Height $=20 \mathrm{~m}$, (Plaxis Output).
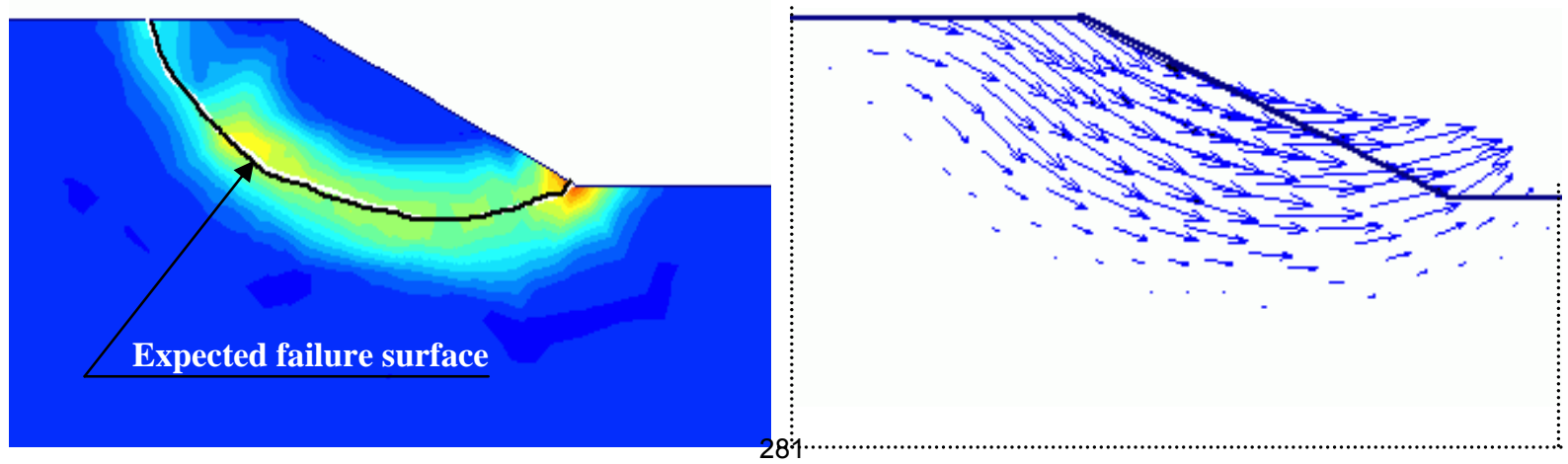
Fig. 2b: Shear Band and Displacement Vectors for Slope with $c=15 \mathrm{kN} / \mathrm{m}^{2}, \phi=20^{\circ}$, Slope Height $=20 \mathrm{~m}$ (Plaxis Output).
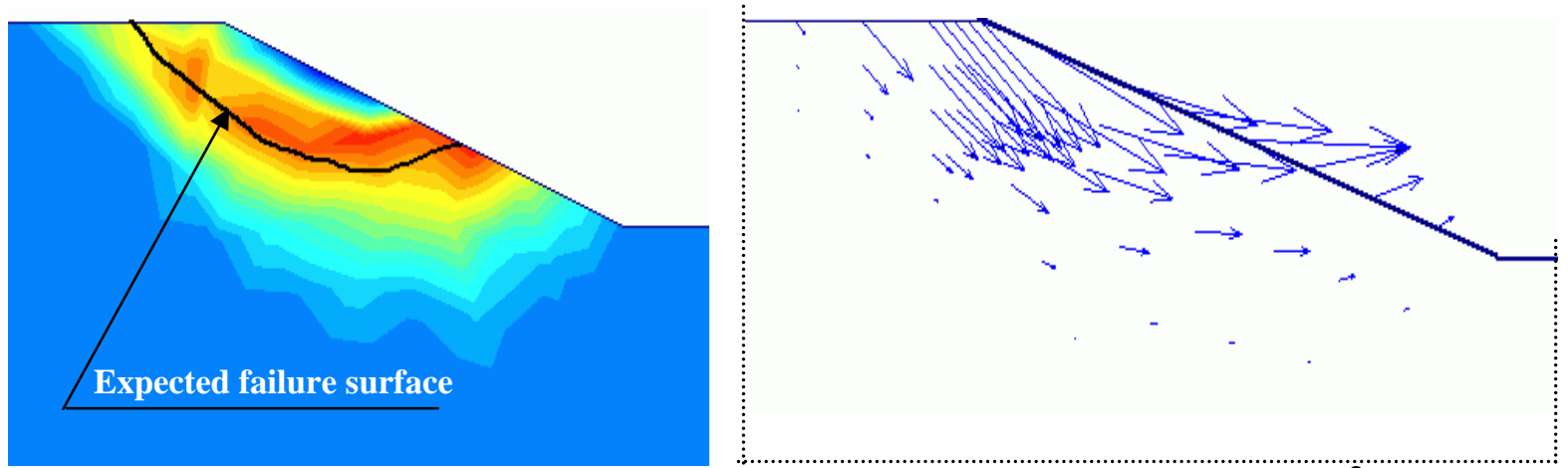

Fig. 3: Shear Band and Displacement Vectors for Slope with $c=5 \mathrm{kN} / \mathrm{m}^{2}, \phi=30^{\circ}$, Slope Height $=10 \mathrm{~m}$, Slope 3:1, (Plaxis Output).
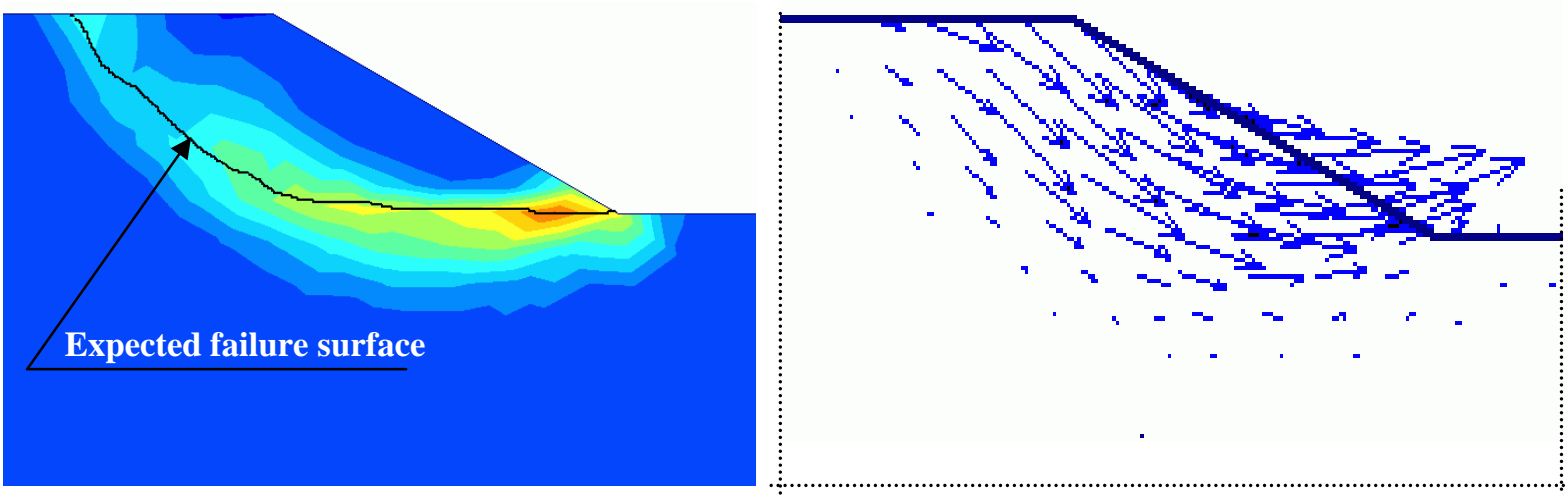

Fig. 4a: Shear Band and Displacement Vectors for Slope with $\mathrm{c}=20 \mathrm{kN} / \mathrm{m}^{2}, \phi=20^{\circ}$, Slope Height = $15 \mathrm{~m}$, Slope 2:1, (Plaxis Output).
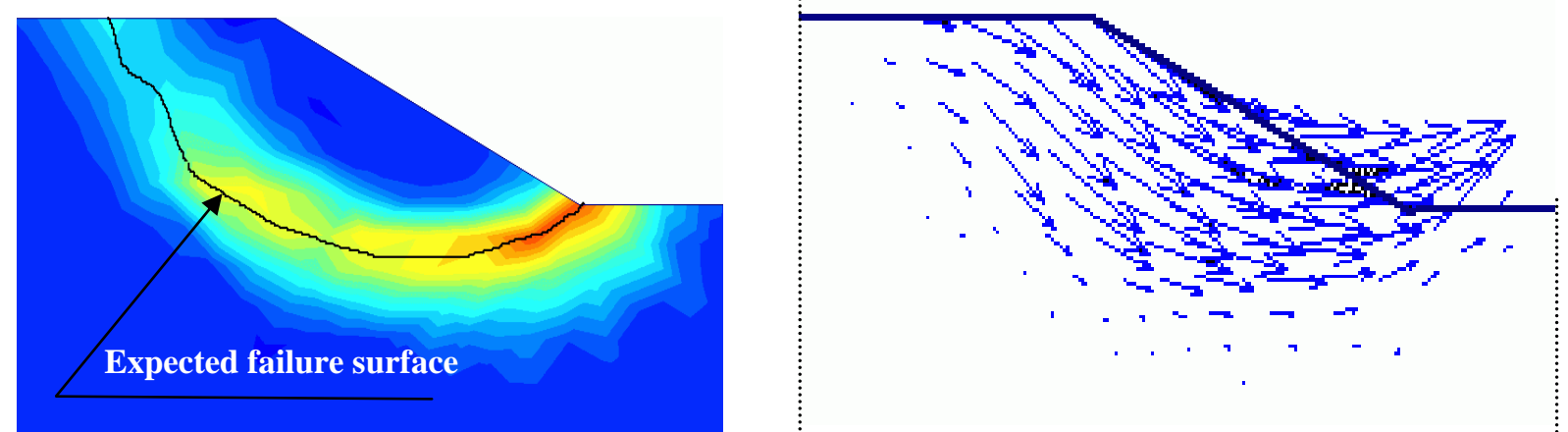

Fig. 4b: Shear Band and Displacement Vectors for Slope with $\mathrm{c}=35 \mathrm{kN} / \mathrm{m}^{2}, \phi=15^{\circ}$, Slope Height $=15 \mathrm{~m}$, Slope 2:1, (Plaxis Output). 


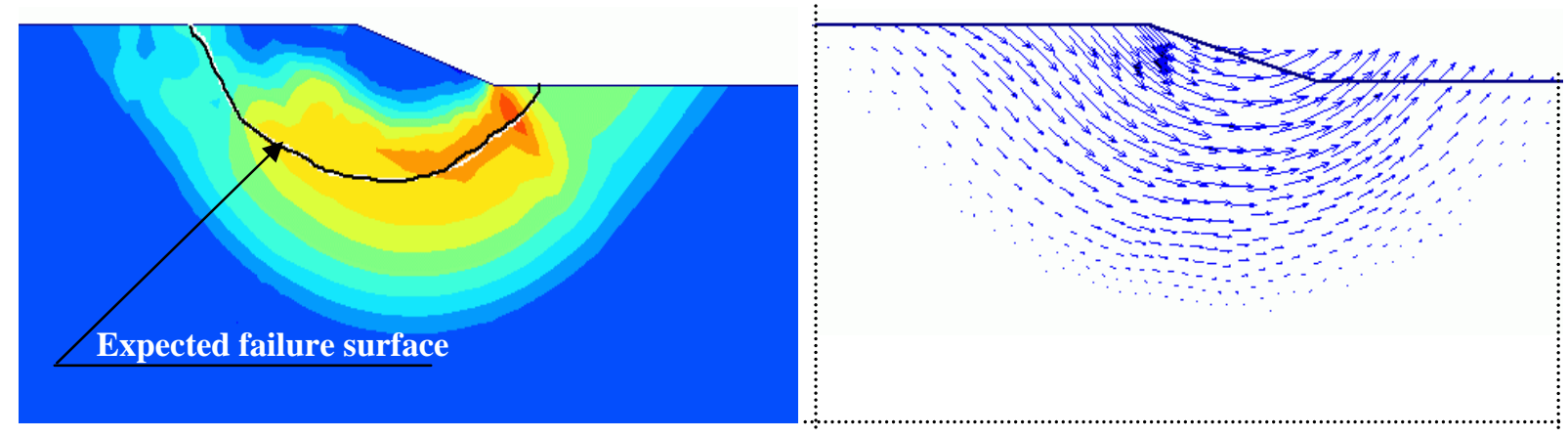

Fig. 5a: Shear Band and Displacement Vectors for Slope with $c=100 \mathrm{kN} / \mathrm{m}^{2}, \phi=5^{\circ}$, Slope Height $=10 \mathrm{~m}$, Slope 3:1 (Plaxis Output).
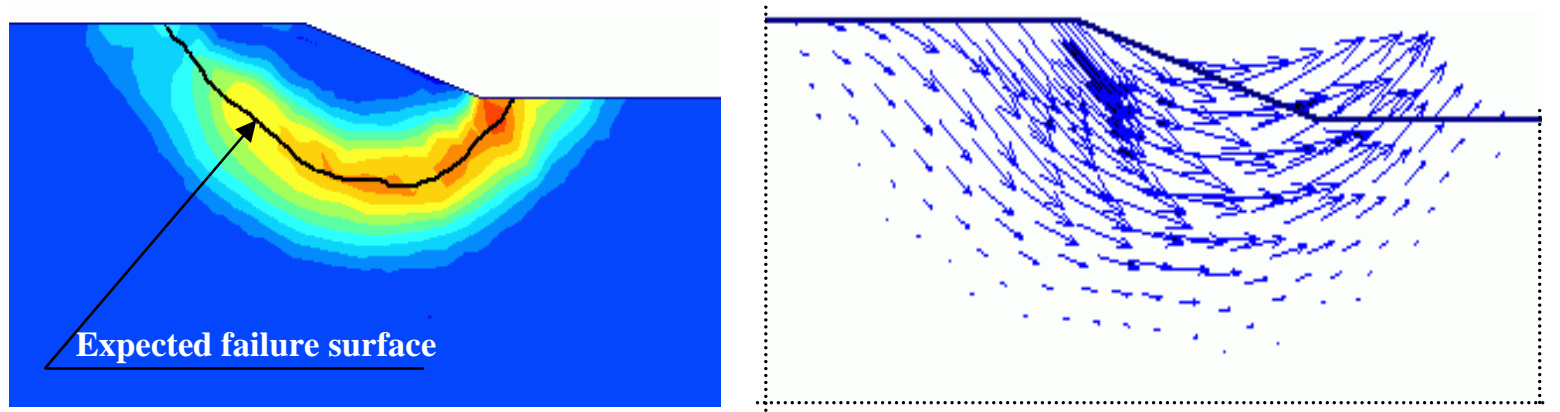

Fig. 5b: Shear Band and Displacement Vectors for Slope with c $=50 \mathrm{kN} / \mathrm{m}^{2}, \phi=5^{\circ}$, Slope Height $=10 \mathrm{~m}$, Slope 3:1 (PLAXIS Outputs).

Zone of stress and displacement

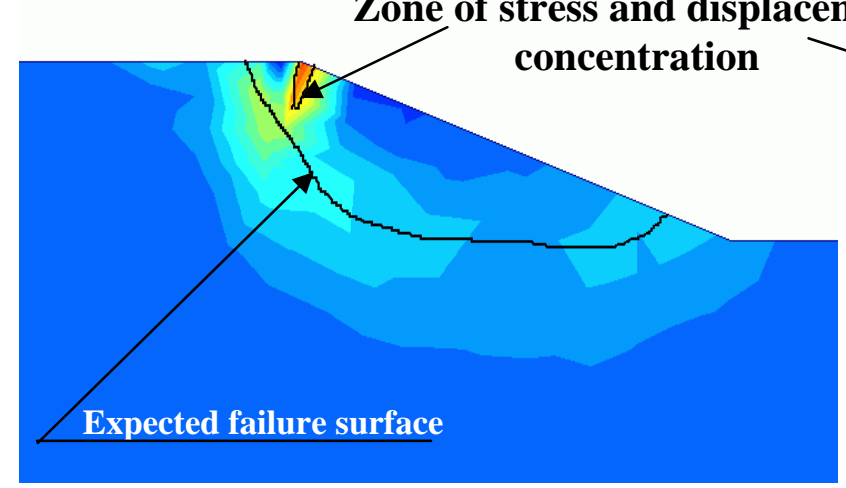

(a) Unloaded

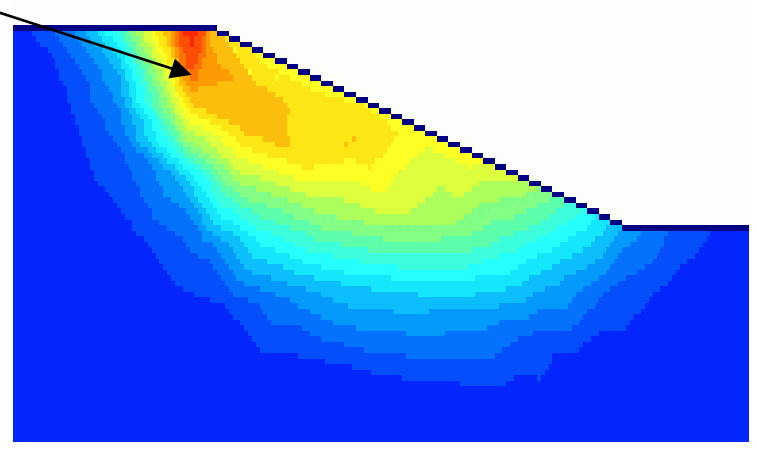

(b) Loaded 
Fig. 6: Shear Band for Slope with $\mathrm{c}=15 \mathrm{kN} / \mathrm{m}^{2}, \phi=20^{\circ}$, Slope Height $=10 \mathrm{~m}$, Slope 3:1, Load Starts at $0.3 \mathrm{H}$ from the Slope Crest, (Plaxis Output).

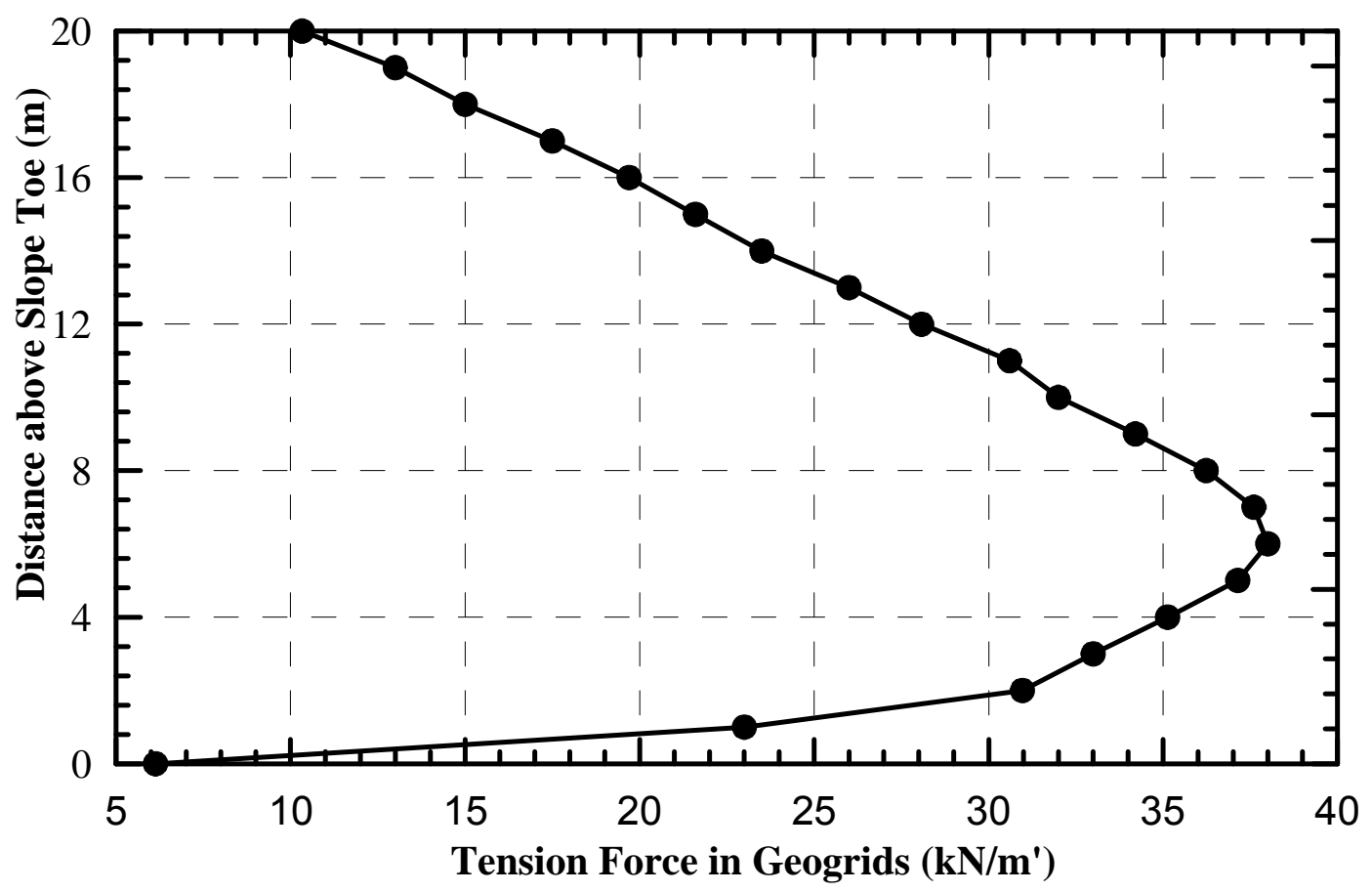

Fig. 7: Relation between Force in Geogrid and above Distance Slope Toe.

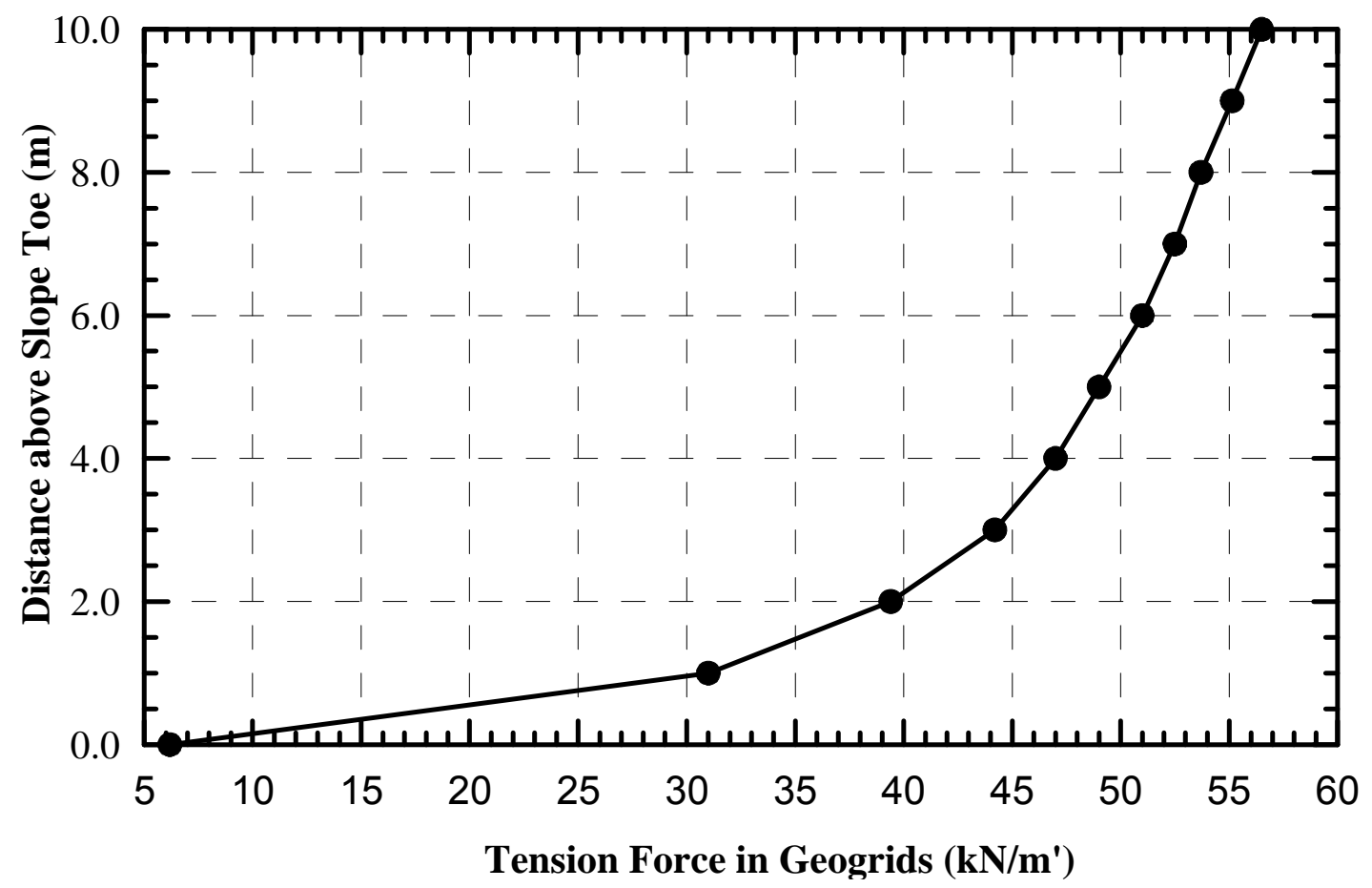


Fig. 8: Relation between Force in Geogrid and Distance above Slope Toe.

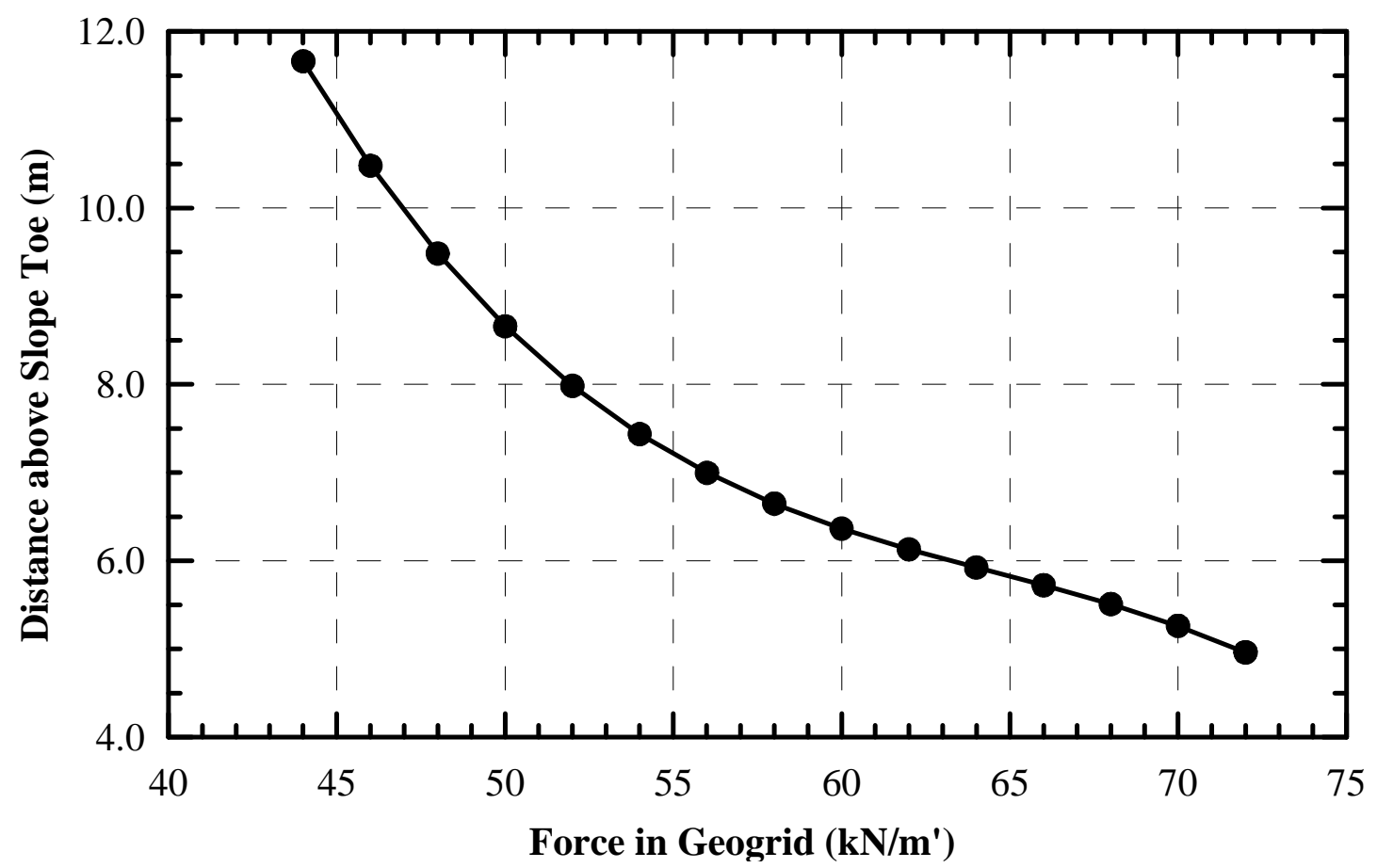

Fig. 9: Relation between Force in Geogrid and Distance above Slope Toe.

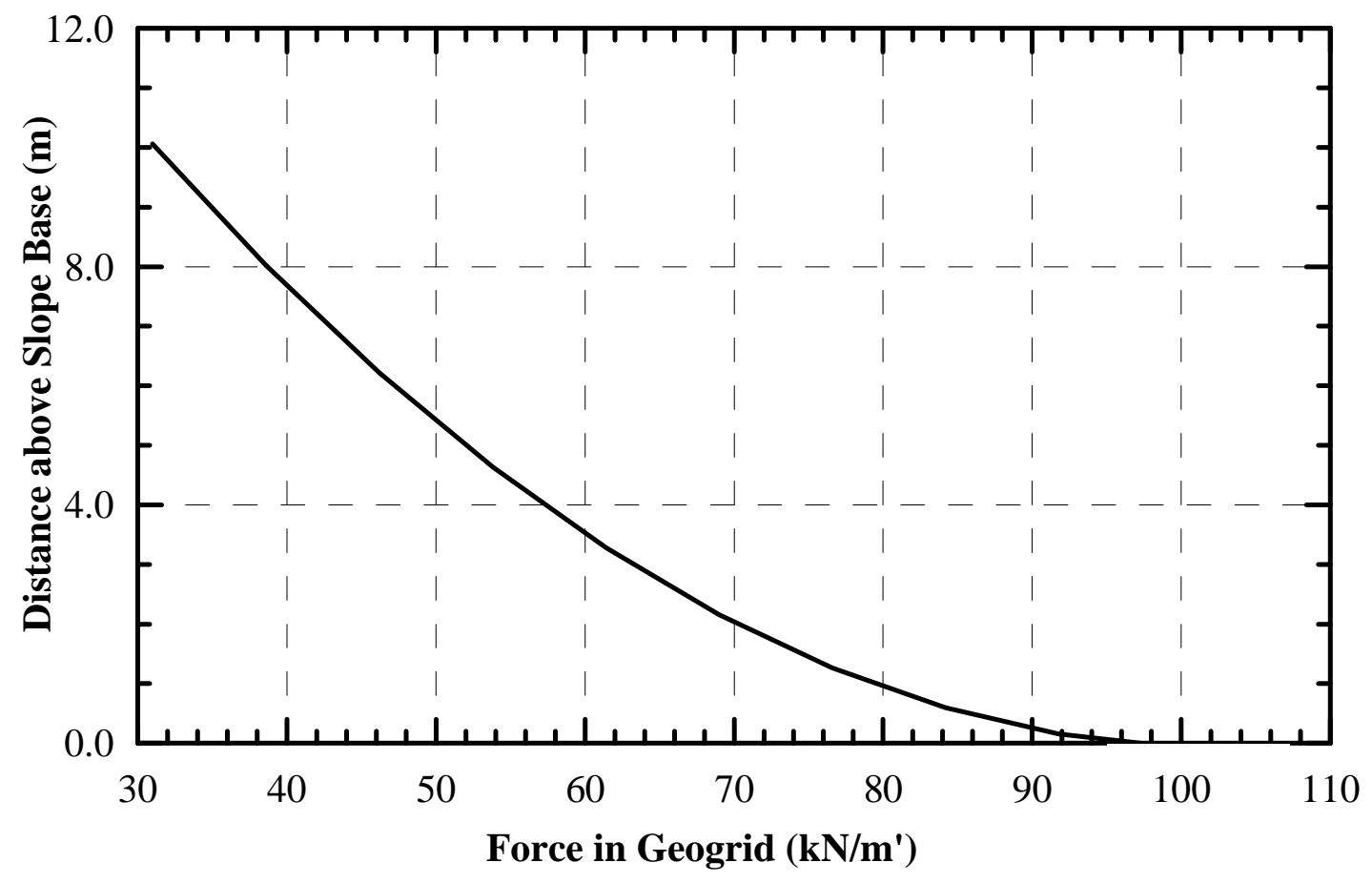


Fig. 10: Relation between Force in Geogrid and Distance above Slope Toe.

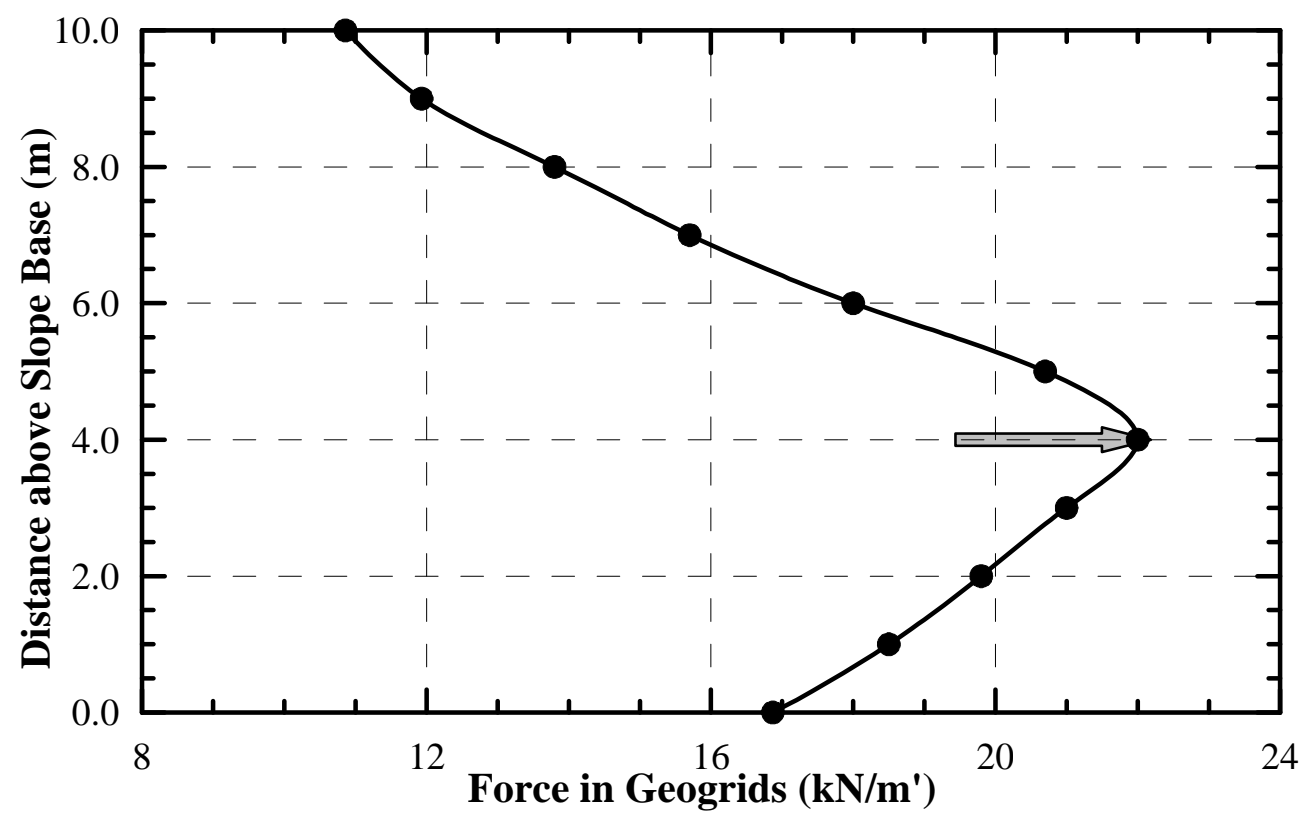

Fig. 11a: Relation between Force in Geogrid and Distance above Slope Toe, Slope 3:1.

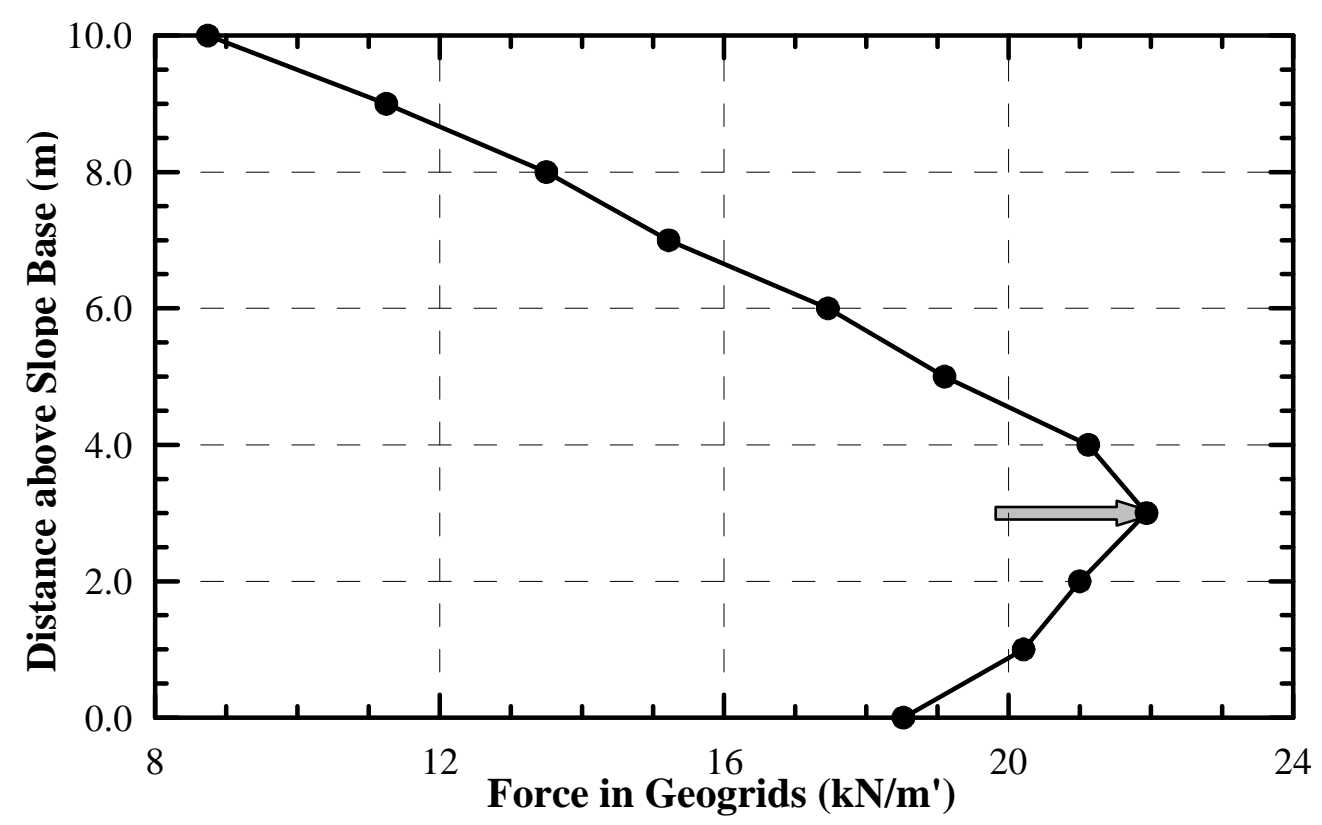


Fig. 11b: Relation between Force in Geogrid and Distance above Toe, Slope 2:1

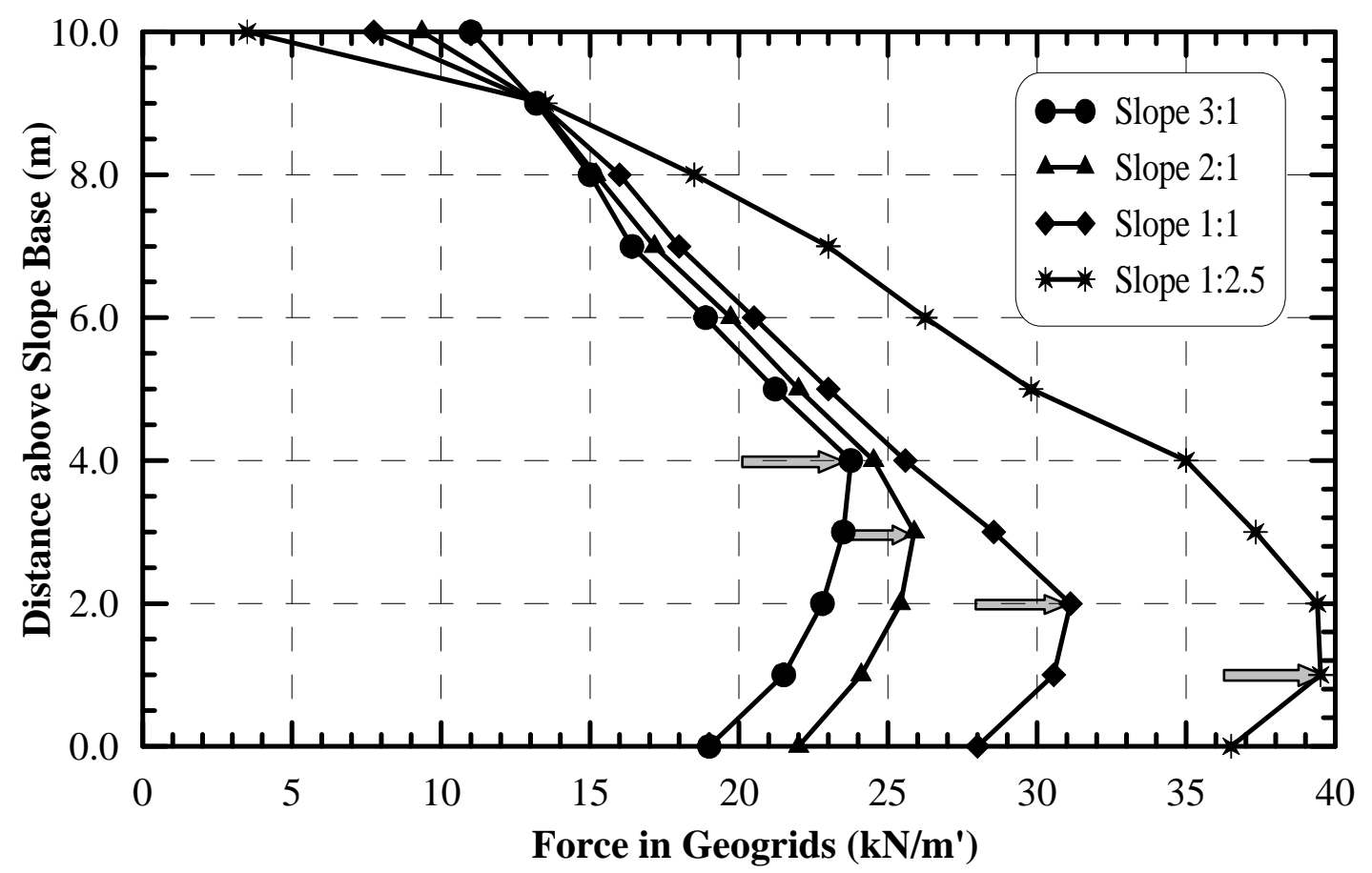

Fig. 12: Relation between Force in Geogrid and Distance for Different Slopes.

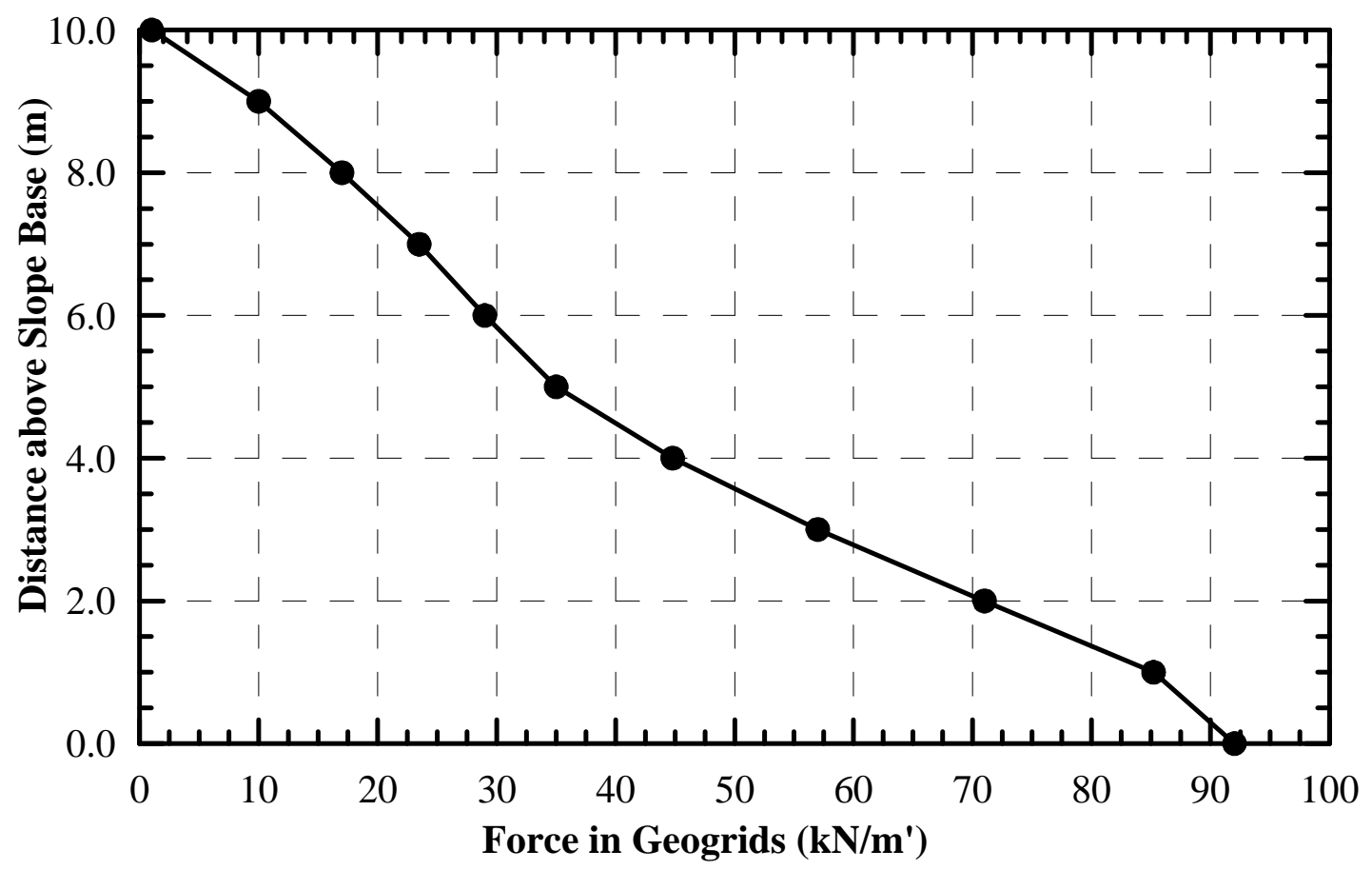


Fig. 13: Relation between Force in Geogrid and Distance for Vertical Cut.

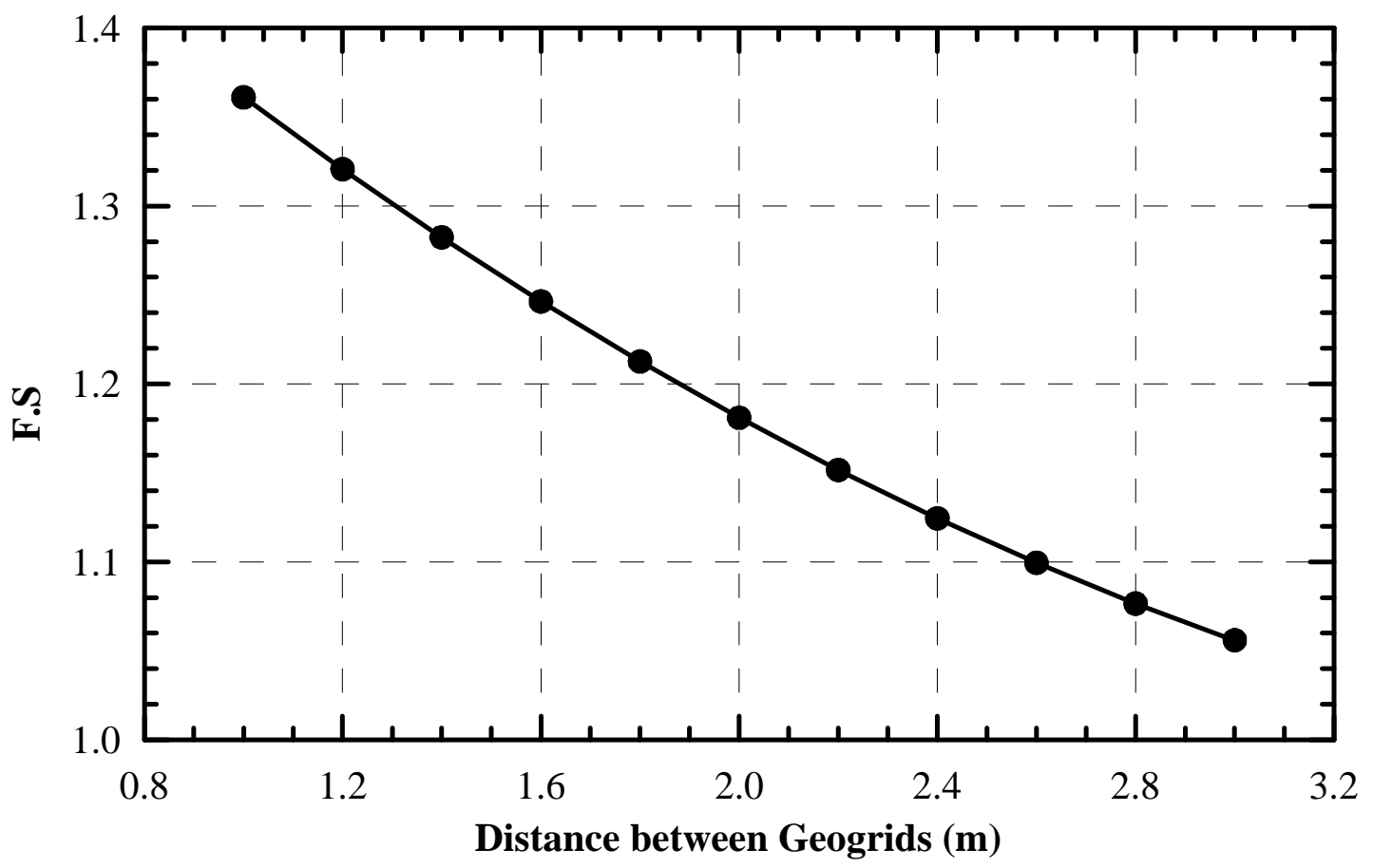

Fig. 14: the Relation between Distance between Geogrids and (F.S), for a Slope with $\mathrm{H}=20 \mathrm{~m}, \beta=63^{\circ}, \mathrm{c}=20 \mathrm{kPa}, \phi=20^{\circ}$. 